\title{
Near infrared analysis as a tool for rapid screening of some major wood characteristics in a eucalyptus breeding program
}

\author{
Henri Baillères $^{\mathrm{a}^{*}}$, Fabrice Davrieux ${ }^{\mathrm{a}}$ and Frédérique Ham-Pichavant ${ }^{\mathrm{b}}$ \\ ${ }^{a}$ CIRAD-Forêt, 73 rue J.F. Breton, Maison de la Technologie, BP 5035, 34032 Montpellier Cedex 1, France

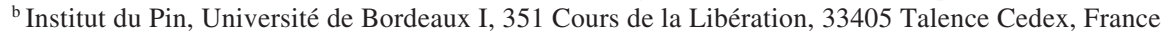

(Received 20 August 2001; accepted 8 July 2002)

\begin{abstract}
The cost and time required to perform traditional chemical and technological tests to assess wood characteristics for breeding programmes is still a major constraint. Near infrared diffuse reflectance spectroscopy (NIRS) is a highly promising method that could be adapted for rapid measurements on wood. In the Congo, the best genotypes for clonal plantations are selected from hybridised eucalyptus full-sib families. From this narrow genetic base, ground wood-meal samples (extractive-free or not) were analysed to determine quantitative relations between NIR spectral bands and extractive content, lignin composition, surface longitudinal growth strain and shrinkage relative to prediction accuracy. The results revealed that NIRS can be used effectively to predict characteristics linked closely with the chemical composition of wood. However, the reference measurements must be accurate and must represent a wide range of values to achieve valid predictions. Methodological and metrological improvements are possible.
\end{abstract}

eucalyptus / breeding / wood properties / near infrared spectroscopy / lignin / shrinkage / longitudinal growth stress

Résumé - La spectroscopie proche infrarouge, outil de diagnostic rapide de quelques propriétés de base pour le bois d'eucalyptus dans un programme d'amélioration génétique. L'évaluation des propriétés du bois à des fins de sélection est généralement entravée par la durée et le coût des essais technologiques. Une des méthodes probablement la plus adaptable aux mesures rapides sur le bois est la spectrométrie en réflexion diffuse dans le proche infrarouge (SPIR). Au Congo, une sélection des meilleurs génotypes pour la plantation clonale est réalisée au sein d'une famille d'eucalyptus de plein frère issue d'une hybridation. Sur cette base génétique étroite, à partir d'échantillons de bois broyé, avant ou après extraction, des relations quantitatives entre les bandes spectrales issues de la SPIR et le taux d'extraits, la quantité et la composition de la lignine, la déformation longitudinale de croissance et les retraits sont analysés en terme de précision de la prédiction. Les résultats obtenus montrent que la SPIR peut être utilisée efficacement pour prédire les caractéristiques qui dépendent étroitement de la constitution chimique du bois. Cependant, la mesure de référence doit être précise et doit représenter la plus large gamme de valeurs pour obtenir des prédictions exploitables. Des améliorations méthodologiques et métrologiques sont envisageables.

spectroscopie proche infrarouge / propriétés du bois / lignine / contraintes de croissance / amélioration génétique

\section{INTRODUCTION}

Wood properties are known to vary between species, and between genotypes within species. This variability is heritable and can be tapped in breeding programmes to obtain varieties with improved wood properties, thus enhancing end-product quality. The ability to assess wood quality is a critical challenge facing the forest industry. In intensively managed forests such as clonal eucalyptus plantations where the raw material is highly heterogeneous $[2,5,11,39]$, it is important to be able to predict wood properties of whole trees using nondestructive sampling techniques. One major hurdle to overcome is the high within-tree variability in wood properties resulting from the harvesting fast growing trees at a young stage, with a high proportion of juvenile and reaction wood $[2,5,11,39]$. Moreover, in breeding programs, selection is generally focused on a narrow genetic base, so there is low between-tree variability in selected traits in contrast with

\footnotetext{
* Correspondence and reprints

Tel.: +33 4676144 51; fax: +33 4676157 25; e-mail: Henri.bailleres@cirad.fr
} 
the high within-species variations that can occur. Predicting the technological properties of interest is a real challenge in these conditions. Unfortunately, the cost and time required to perform traditional chemical and technological tests to assess wood characteristics for breeding programmes is still a major constraint. Near infrared diffuse reflectance spectroscopy (NIRS) is a highly promising method that could be adapted for rapid measurements on wood.

NIRS analysis is a fast, environment-friendly analytical method that has gained widespread acceptance in recent years. It is based on vibrational spectroscopy that monitors changes in molecular vibrations intimately associated with changes in molecular structure. Spectra within the NIR region consist of overtone and combination bands of fundamental stretching vibrations of functional groups that occur in the middle infrared region, mainly $\mathrm{CH}, \mathrm{OH}$ and $\mathrm{NH}$, which represent the backbone of all biological compounds. NIRS has a substantial edge over other indicators because the spectra contain information about all chemical constituents of organic material. This advantage eliminates the need to initially pinpoint the key factor that determines a specific characteristic. NIRS instruments must be calibrated using standard laboratory reference methods. A calibration model can thus be developed by calculating the regression equation based on NIR spectra and the known reference information. The NIRS system is calibrated on the basis of a set of fully characterized samples and mathematical models with high prediction accuracy. The sample set must be representative of the variability of the population targeted for the prediction.

There is a broad range of analytical applications of NIRS: several industries use NIRS, e.g. agriculture, food, petrochemical, polymer and textile industries [9, 20, 35]. This technology is also being used to an increasing extent in forest and wood sciences. For wood products, NIRS is mainly used for rapid prediction of pulp yield and pulping characteristics $[11,15,21,26,28,36]$. NIRS technology is now being developed and calibrated to replace classical wet-chemical methods for wood applications. In addition, a few studies have used NIRS to assess physical and mechanical properties such as basic density, stiffness and strength [15, 27, 32]. In the forest product literature, to our knowledge there is no reference to the use of NIRS to assess characteristics such as extractive content, the monomeric composition of lignin, shrinkage or the extent of longitudinal growth stress.

This paper evaluates the potential of NIRS for the assessment of some major chemical, physical and mechanical wood characteristics within a eucalyptus full-sib hybridised family. Our objective was to measure prediction accuracy under real operational conditions, i.e. selection within a full-sib family involves working with low between-tree variability in wood characteristics and consequently requires accurate reference methods.

\section{MATERIALS AND METHODS}

\subsection{Sample origins}

An interspecific hybrid progeny of E. urophylla $\times E$. grandis from the URPPI ${ }^{(1)}$ genetic improvement program was examined in this study. A total of 200 full-sibs were available for measurement. The trees were planted in 1992 and felled in 1998 at 59 months old. Logs were cut at $1.3 \mathrm{~m}$, and half and three-quarters of the commercial height.

\subsection{Sampling method}

Two sets of measurements were performed:

(a) On each tree, a disk was taken for chemical analysis at half of the commercial height. A total of 193 disks were sampled.

(b) On a subpopulation of 13 trees, chosen for their high and low longitudinal growth stress (LGS) values, 93 small prismatic samples were taken at $1.3 \mathrm{~m}$ to adjust for LGS and shrinkage. The samples $(15 \times 20 \times 30 \mathrm{~mm}$ in R, T, L planes) were cut close to where the LGS measurement was obtained, on the same longitudinal axis at the periphery of the tree. Chemical analyses and shrinkage measurements were performed on these extreme stress value samples.

The samples were ground into wood meal (mesh 40) and then stored in a room under controlled conditions (30\% relative humidity and $25^{\circ} \mathrm{C}$ ) in order to obtain a fixed wood moisture content of $6 \%$.

The meal was mixed and then $15 \mathrm{~g}$ was removed with a spatula for disk samples and about $5 \mathrm{~g}$ for extreme value samples and placed in a sample cup. After the samples had been scanned under a near infrared spectrometer, the sample cup was emptied and then refilled using the same procedure to obtain a duplicate sample. This procedure was used on extracted and nonextracted wood meal for disk samples and on nonextracted wood meal for extreme value samples.

\subsection{Chemical analysis}

\subsubsection{Rationale}

Lignin is an undesirable component in the conversion of wood into pulp and paper. Lignin removal is a major step in the papermaking process. Lignin content is an important determinant with respect to cellulose fiber extraction from wood. Lignin subunit composition influences cellulose accessibility. Breeders are thus seeking ways to reduce extractive content and/or lignin content or modify the monomeric composition to improve pulp manufacturing. Hardwood lignins are copolymers of syringyl (S) and guaiacyl (G) units. Softwood lignins are essentially composed of guaiacyl units, except for compression wood lignins, which are p-hydroxyphenyl (H) - guaiacyl copolymers. The presence of methoxylated S units facilitates chemical delignification during pulp manufacturing but this is not the only structural parameter which affects Kraft cooking [10].

(1) For the past 30 years, URPPI (Unité de Recherches pour la Productivité des Plantations Industrielles), in collaboration with CIRAD-Forêt, have been managing an eucalyptus genetic improvement programme in the Congo. The research results on silviculture, vegetative multiplication and varietal creation using interspecific hybridisation have made it possible to establish 46000 ha of industrial plantations. 


\subsubsection{Extractive content}

The analyses focused on the overall content of extractive material (EC) obtained by acetone-ethanol-water extraction relative to that obtained by the modified TAPPI T 204 om- 88 procedure.

The extractions were performed in a Soxhlet apparatus using the acetone-ethanol 2:1 $\rightarrow$ ethanol $\rightarrow$ water solvent sequence, which makes it possible to eliminate soluble phenols and other extractive compounds not linked to the cell walls. The residues were dried in an oven at $105 \pm 3{ }^{\circ} \mathrm{C}$ to constant weight and then weighed. The extractive content was calculate as follows:

$$
\mathrm{EC}(\%)=\frac{\mathrm{W} 0-\mathrm{W} 1}{\mathrm{WO}} \times 100
$$

where:

$\mathrm{W} 0=$ oven-dried weight of nonextracted wood;

$\mathrm{W} 1$ = oven-dried weight of extractive-free wood.

Extractive contents of extreme value samples derived from sapwood were not determined because of their very low extractive material contents.

\subsubsection{Lignin content and composition}

Klason lignin content was measured according to Tappi T222 om-83 and the modified procedure of Effland [12]. This technique involves two phases:

(1) Hydrolysis with $72 \% \mathrm{H}_{2} \mathrm{SO}_{4}$ for $2 \mathrm{~h}$ at $20{ }^{\circ} \mathrm{C}$.

(2) Hydrolysis with $3 \% \mathrm{H}_{2} \mathrm{SO}_{4}$ performed on a hot plate, with a 4-h boiling period. The insoluble residue, expressed as a percentage of the extractive-free oven-dried wood $\left(105 \pm 3{ }^{\circ} \mathrm{C}\right.$ to constant weight), obtained after filtration, washing and drying, corresponded to the Klason lignin content.

Lignins were characterized by thioacidolysis. Thioacidolysis is an efficient procedure to estimate the amount and the monomeric composition ( $\mathrm{S}, \mathrm{G}$ and $\mathrm{H}$ units) of uncondensed structures in lignins by cleavage of arylglycerol- $\beta$-aryl ether bonds. As a single method, thioacidolyse has a definite advantage in that it may be used to characterize unambiguously typical and prominent lignin structures [22]. Thioacidolysis involves solvolysis of $15 \mathrm{mg}$ of extractive-free wood in a dioxane/ethanethiol mixture $(9 / 1, \mathrm{v} / \mathrm{v})$ containing $0.2 \mathrm{M}$ of boron trifluoride etherate, for $4 \mathrm{~h}$ in an oil bath at $100{ }^{\circ} \mathrm{C}$. The thioacidolysis recovered monomers were quantified by $\mathrm{GC}$ of their trimethylsilylated derivatives [22].

\subsection{Physical and mechanical properties}

\subsubsection{Rationale}

Two physical and mechanical properties were measured because of their impact on eucalyptus timber value. On the one hand, longitudinal growth stress, which is an intrinsic property of wood, can explain the considerable internal effort - generally known as "growth stresses" - sustained by wood of standing trees. These stresses are released during processing operations (from felling to grading) and can damage the wood by causing end splits, warping and broken boards (major problems for eucalyptus), as explained by [16]. On the other hand, shrinkage, generally related to LGS [13], whose intensity and heterogeneity are linked to the dimensional stability of wood products.

\subsubsection{Surface longitudinal growth strain (LGS)}

Growth stresses originate from surface growth strains induced in the cambial layer during the differentiation and maturation of new cells and impeded by the mass of the whole trunk. These stresses help to reorient the tree in a more favorable position. Longitudinal growth strain at the stem surface is appraised on the basis of stress released on the stem periphery by drilling into wood under the cambium [1-3].

LGS was measured using a unidirectional mechanical sensor designed by CIRAD-Forêt [3]. It measures the distance between two reference points before and after drilling a hole equidistant from these two points. This method is known as the "single hole method", and was described by [1].

\subsubsection{Shrinkage}

Longitudinal (LS), radial (RS) and tangential (TS) shrinkages were measured in green (undried) samples and ovendried samples (6\% moisture content). Shrinkage was measured using a special device based on a non-contact laser-optical displacement measurement (optoNCDT 1605.10 from MicroEpsilon). The results are expressed as a ratio of the difference between green and ovendried dimensions to the ovendried dimension:

$$
\mathrm{XS}=\frac{\mathrm{XO}-\mathrm{XG}}{\mathrm{XO}}
$$

where:

XS: shrinkage in the $\mathrm{X}=\mathrm{L}, \mathrm{R}$ or $\mathrm{T}$ plane;

$\mathrm{XO}$ : dimensions of the sample at $6 \%$ moisture content;

$\mathrm{XG}$ : dimensions of the green sample.

After the shrinkage measurements, the samples were ground for NIRS measurements.

\subsection{Near infrared spectroscopic (NIRS) technique}

NIR spectra were collected in reflectance mode using a Foss-Perstorp 6500 spin cell apparatus. Spectral data acquired in diffuse reflection between 400 and $2500 \mathrm{~nm}$ (visible and close infrared), with a step at $2 \mathrm{~nm}$, were processed with the NIRS 2 v. 4.11 software package (InfraSoft International).

A $16 / 32$ sequence (16 measurements of the reference ceramic then 32 measurements of the sample) was obtained for each sample. The absorbance spectrum, represented as a log value(1/R), was obtained by averaging these measurements and comparing them to the reference. Each sample was analysed twice (two powder samples). The RMS (root mean square) [20] values considered for random samples taken within each sub-group of sub-samples ranged from 180 to 700 , mean of around 300. These values, calculated according to the spectra second derivatives, reflected the spectral reproducibility within the range set by the manufacturer, i.e. 800 for powder products.

The spectral matrix (X matrix), which is $\mathrm{n}$ lines (each representing a tested sample) and $\mathrm{p}$ rows (absorbances at wavelengths in the NIR spectra $\left[\mathrm{x}_{1}, \mathrm{x}_{2}, \ldots, \mathrm{x}_{\mathrm{p}}\right]$, was used to determine the generalised Mahalanobis distance [33]. This parameter, calculated on the basis of a principal components matrix derived from a principal component analysis (PCA) of the spectral matrix, is a powerful tool for defining sample boundaries and similarity indices between spectra. Mahalanobis distance is used as a spectrum outlier tool to detect instrumental error, sample contamination, differences in sample handling, etc.

Predictions were made on an independent set of samples to assess the best portions of the electromagnetic spectrum [8], and the results were analysed with different statistical tests to determine the most accurate procedures. Partial least squares regression (PLS), as described by [31], was then applied to obtain mathematical models 
comparing the spectral data ( $\mathrm{X}$ matrix) and the reference laboratory data. The latter is the $\mathrm{Y}$ matrix, which is $\mathrm{n}$ lines (each representing a tested sample) and q rows (each representing a reference variable in this study of EC, LK, S/G, LGS, TS, RS and LS). Like the principal components regression, the PLS method involves regression of the predictive variable $y$ on variables $\mathrm{t}_{1}, \mathrm{t}_{2}$, etc., which are latent variables (linear combinations of $\mathrm{x}_{1}, \mathrm{x}_{2}, \ldots, \mathrm{x}_{\mathrm{p}}$ ). However, in the PLS method, the latent variables are obtained by taking $\mathrm{y}$ into account and the predictive variables $\mathrm{x}_{1}, \mathrm{x}_{2}, \ldots, \mathrm{x}_{\mathrm{p}}$, whereas in the principal components regression method, the latent variables (i.e. the principal components themselves) are obtained by only taking information derived from the predictive variables into account. The model obtained with the PLS method is therefore always more "economical" in comparison to that obtained using the principal components regression method. Economy, in this context, means that there is a relatively low number of latent variables, so the results are easier to interpret and the model is more stable. The optimum number of PLS terms was determined by cross-validation. The sample set was divided into four groups. The model was developed from three groups, with the remaining group serving to validate the model. The operation was reproduced four times, i.e. four subgroups for four cross-validations. The standard error of cross-validation (SECV) was the sum of errors for the three predictions - it enabled noise separation and thus avoided overfitting [35]. The correct number of regression factors for the PLS model was determined by the minimum mean square error of internal cross-validation [17].

After cross-validation, all samples were calibrated using the number of factors determined by cross-validation. The SEP was estimated by predicting a set of 30 samples, with a random choice within the population, through the calibration carried out on the remaining samples.

Outlier detection was based on the Student's t test for residual variability (difference between the NIRS analysis and reference analysis results). This test assesses the variation between an NIRS value and its laboratory reference value. Moreover, $t$ values greater than 2.5 were considered significant and samples with significant values were possible outliers.

\subsection{Calibration statistics}

Calibration performance in terms of data fitting and prediction accuracy was expressed by the coefficient of multiple determination $\left(\mathrm{R}^{2}\right)$, the standard error of calibration (SEC) and the standard error of prediction (SEP):

$$
\mathrm{SEC}=\sqrt{\frac{\sum_{\mathrm{i}=1}^{\mathrm{N}_{C}}\left(\mathrm{Y}_{\mathrm{i}}-\hat{\mathrm{Y}}_{\mathrm{i}}\right)^{2}}{\mathrm{~N}_{\mathrm{C}}-\mathrm{k}-1} .} .
$$

This statistic represents the SD for residual variations due to differences between actual (primary laboratory analytical values) and NIRS predicted values for samples within the calibration set. $\hat{Y}_{i}$ is the value of the constituent of interest for a validation sample $i$ estimated using the calibration, $\mathrm{Y}_{\mathrm{i}}$ is the known value of the constituent of interest of sample $i, \mathrm{~N}_{\mathrm{C}}$ is the number of samples used to obtain the calibration, and $k$ is the number of factors used to obtain the calibration.

$$
\mathrm{SEP}=\sqrt{\frac{\sum_{\mathrm{j}=1}^{\mathrm{N}_{\mathrm{P}}}\left(\mathrm{Y}_{\mathrm{j}}-\hat{\mathrm{Y}}_{\mathrm{j}}\right)^{2}}{\mathrm{~N}_{\mathrm{P}}-1} .}
$$

This statistic represents the SD for residual variations due to differences between actual (primary laboratory analytical values) and
NIRS predicted values for samples outside of the calibration set using a specific calibration equation (set of $\mathrm{N}$ independent samples). $\hat{\mathrm{Y}}_{\mathrm{j}}$ is the value of the constituent of interest for sample $j$ predicted by the calibration, $\mathrm{Y}_{\mathrm{j}}$ is the known value of the constituent of interest for sample $j$, and $\mathrm{N}_{\mathrm{p}}$ is the number of samples in the prediction set.

The ratio of performance to deviation (RPD: ratio of the SD of the reference results to SEP) is a measurement of the ability of an NIRS model to predict a constituent [34]. Reporting the SEP alone may be misleading unless it is reported by comparison with the SD of the original reference data. If the SEP is close to the SD, then the NIRS calibration is not efficiently predicting the composition or functionality. If SEP $=\mathrm{SD}$, the calibration is essentially predicting the population mean. An RPD below 2 cannot give a relevant prediction. An RPD value of 2.0-3.0 is regarded as adequate for rough screening. A value of above 3.0 is regarded as satisfactory for screening (for example in plant breeding), values of 5 and upward are suitable for quality control analysis, and values of above 8 are excellent, and can be used in any analytical situation.

\section{RESULTS}

The RMS values obtained for two different samples were 2- to 3-fold higher than the RMS values obtained for two sub-samples. These results indicate greater intersample than intrasample variability. On this basis, the mean spectrum for the two sub-samples were retained for the rest of the study.

\subsection{Typical spectrum for extracted and nonextracted samples}

The spectra obtained for extracted and nonextracted samples were not significantly different (figures 1 and 2). The major absorbance bands were similar for both spectra, and only the total energy absorbed differed. Band variations for both spectra were mainly observed in the regions of the two water bands (1350-1450 nm and 1848-1968 nm) and 2050-2150 nm. Band variations near $2000 \mathrm{~nm}$ were due to $\mathrm{OH}$ stretching combined with $\mathrm{OH}$ and $\mathrm{CH}$ deformation bonds in the polysaccharide cellulose and xylan, and bands near $2132 \mathrm{~nm}$ were due to $\mathrm{C}_{\mathrm{ar}}-\mathrm{H}$ stretching combined with $\mathrm{C}=\mathrm{C}$ stretching of lignin and extractives. Other minor bands were also detected (table I).

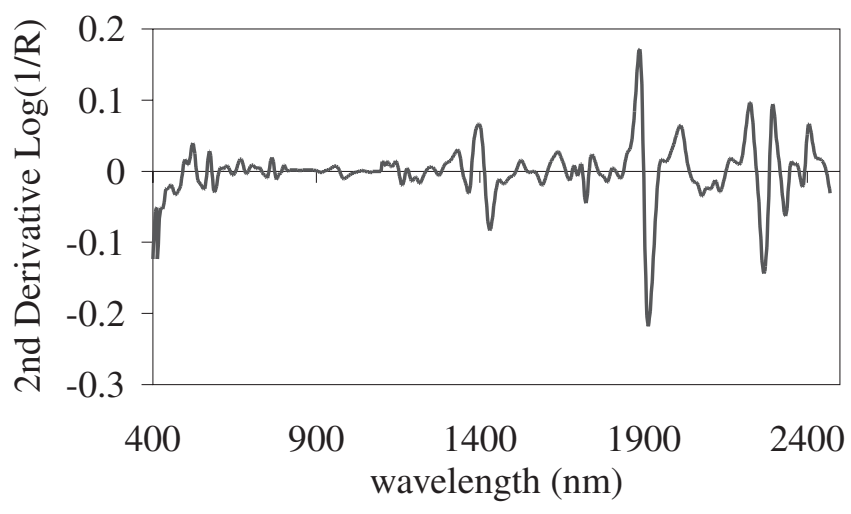

Figure 1. NIR reflectance spectrum for nonextracted powder. 


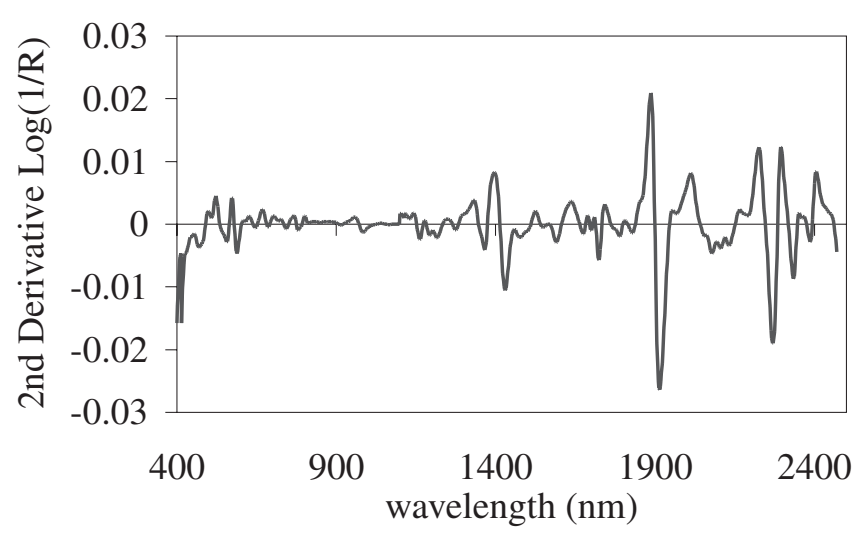

Figure 2. NIR reflectance spectrum for extracted powder.

Table I. Chemical assignment of the major absorbance bands in the 400-2500 $\mathrm{nm}$ region of the eucalyptus NIR spectrum [18].

\begin{tabular}{|c|c|c|}
\hline $\begin{array}{l}\text { Wavelength } \\
(\mathrm{nm})\end{array}$ & Bond vibration & Structure \\
\hline 524 & Electronic vibrations & Green color \\
\hline 574 & Electronic vibrations & Green color \\
\hline 668 & Electronic vibrations & Red color \\
\hline 1394 & $\mathrm{CH}$ stretch $\mathrm{CH}_{2}$ bend & $\mathrm{CH} 2$ \\
\hline 1520 & $\mathrm{O}-\mathrm{H}$ stretch first overtone & $\mathrm{CONH}_{2}$ \\
\hline 1616 & $\mathrm{C}-\mathrm{H}$ stretch first overtone & $=\mathrm{CH}_{2}$ \\
\hline 1688 & $\mathrm{C}-\mathrm{H}$ stretch first overtone & Aromatic \\
\hline 1724 & $\mathrm{C}-\mathrm{H}$ stretch first overtone & $\mathrm{CH}_{2}$ \\
\hline 1740 & S-H stretch first overtone & $-\mathrm{SH}$ \\
\hline 1782 & $\mathrm{C}-\mathrm{H}$ stretch first overtone & Cellulose \\
\hline 1896 & $\mathrm{O}-\mathrm{H}$ stretch $\mathrm{C}-\mathrm{O}$ stretch & $\mathrm{C}=\mathrm{O}, \mathrm{CO}_{2} \mathrm{H}$ \\
\hline 1910 & $\mathrm{O}-\mathrm{H}$ stretch first overtone & $\mathrm{Ar}-\mathrm{OH}$ \\
\hline 1992 & $\mathrm{~N}-\mathrm{H}$ stretch bend combination band & Amino acids \\
\hline 2028 & $\mathrm{C}=\mathrm{O}$ stretch second overtone & $\mathrm{CONH}_{2}$ \\
\hline 2074 & $\mathrm{~N}-\mathrm{H}_{2}$ deformation second overtone & Amide II \\
\hline 2266 & $\mathrm{O}-\mathrm{H}$ C-O combination bands & Cellulose \\
\hline 2280 & $\mathrm{C}-\mathrm{H} \mathrm{CH}_{2}$ deformation combination bands & $\mathrm{CH}_{3}$, starch \\
\hline 2296 & $\mathrm{C}-\mathrm{H}$ stretch bend second overtone & Protein \\
\hline 2332 & $\mathrm{C}-\mathrm{H}$ stretch, $\mathrm{C}-\mathrm{H}$ deformation & Cellulose, starch \\
\hline 2386 & $\begin{array}{l}\mathrm{C}-\mathrm{O} \text { stretch } \mathrm{O}-\mathrm{H} \text { deformation } 2 \mathrm{nd} \\
\text { overtone }\end{array}$ & $\begin{array}{l}\text { Primary alcohols } \\
\text { ROH }\end{array}$ \\
\hline
\end{tabular}

\subsection{Prediction of the chemical composition: EC, KL and $\mathrm{S} / \mathrm{G}$}

The descriptive statistics for criteria analysed in the laboratory for these powder samples are presented in tables II and III. The EC, KL and S/G ratio distributions were Gaussian. The accuracy of the reference method based on a reproducibility test was in accordance with the published data $[22,23,25]$.
Table II. Descriptive statistics for extractive content (EC), S/G ratio and Klason lignin content (KL) for the entire set of disk samples. $\mathrm{N}$ : total number of samples statistically analysed; $\mathrm{M}$ : mean; $\mathrm{SD}$ : standard error (deviation) for the $\mathrm{x}$ values (reference values); SEL: standard error (deviation) for the laboratory data (reference method) for 8 replications with the same control sample.

\begin{tabular}{lccccc}
\hline Criteria & $\mathrm{N}$ & $\mathrm{M}$ & Range & SD & SEL \\
\hline EC $(\%)$ & 192 & 3.70 & $2.30-5.76$ & 0.62 & 0.34 \\
KL $(\%)$ & 193 & 24.62 & $22.33-26.75$ & 0.84 & 0.42 \\
S/G ratio & 193 & 4.03 & $2.89-5.82$ & 0.54 & 0.08 \\
\hline
\end{tabular}

Table III. Descriptive statistics for extractive content (EC), S/G ratio and Klason lignin content $(\mathrm{KL})$ for the entire set of extreme value samples.

$\mathrm{N}$ : total number of samples statistically analysed; M: mean; SD: standard error (deviation) for the $\mathrm{x}$ values (reference method values); SEL: standard error (deviation) for the laboratory data (reference method) for 9 replications with the same control sample.

\begin{tabular}{lccccc}
\hline Criteria & $\mathrm{N}$ & $\mathrm{M}$ & Range & SD & SEL \\
\hline KL $(\%)$ & 92 & 26.36 & $22.79-30.36$ & 1.43 & 0.58 \\
S/G ratio & 91 & 3.32 & $2.59-4.95$ & 0.47 & 0.1 \\
\hline
\end{tabular}

\subsubsection{From disks}

The models (tables $I V$ and $V$ ) developed on the basis of the laboratory reference and the mean spectrum recorded for nonextracted and extractive-free powder closely fitted the data. The coefficients of determination calculated by comparison of the reference values and those predicted by the NIRS equations were all above 0.85 , except for the EC value for extractive-free wood $\left(R^{2}=0.75\right)$.

$\mathrm{EC}, \mathrm{KL}$ content and the S/G ratio were predicted for a randomised set of about thirty samples using an equation previously formulated for non-extracted and extractive-free wood (tables VI and VII). This procedure enabled us to estimate the SEP for an independent set of samples. These validation sets were representative of actual values for the three criteria within the original population - indeed, the statistical results (mean and SD) for these samples were comparable to those of the population from which they originated (table II). Samples were withdrawn from the validation set because they were outliers in $\mathrm{Y}$ ( $\mathrm{t}$ test) during calibration for the whole population (see Section 2.5). This explains the difference between the number of samples available and the number of samples used in the calibration and validation sets for all criteria.

The standard error of prediction, estimated from the validation sets, were around 0.3 for all criteria. Values estimated for SEP and SECV were close for each criterion, indicating that the introduction of the given number of PLS terms ( $\mathrm{ta}$ bles $I V$ and $V$ ) did not cause an overfitting effect and that the calibration model seemed valid. The coefficients of determination (figures 3, 4, 5, 7 and 8) were all near 0.8 except for 
Table IV. Statistics of the equations developed for the nonextracted disk samples.

$\mathrm{N}$ : total number of samples statistically analysed; M: mean; $\mathrm{R}^{2}$ : coefficient of multiple determination; SD: standard error (deviation) for x values (reference method values); SEC: standard error of calibration; SECV: standard error of cross-validation; SEL: standard error for the laboratory data (reference method) for 8 replications with the same control sample; SEP: standard error of prediction; RPD: ratio of performance to deviation.

\begin{tabular}{lcccccccccc}
\hline Criteria & $\mathrm{N}$ & $\mathrm{M}$ & $\mathrm{SD}$ & $\mathrm{SEC}$ & $\mathrm{R}^{2}$ & SECV & SEL & SEP & Number of PLS terms & RPD \\
\hline EC $(\%)$ & 191 & 3.70 & 0.62 & 0.20 & 0.87 & 0.27 & 0.34 & 0.28 & 8 & 2.2 \\
KL $(\%)$ & 188 & 24.6 & 0.82 & 0.29 & 0.87 & 0.37 & 0.42 & 0.36 & 8 \\
S/G ratio & 190 & 4.03 & 0.53 & 0.17 & 0.90 & 0.22 & 0.08 & 0.22 & 2.3 & 10 \\
\hline
\end{tabular}

Table V. Statistics for equations formulated for the extractive-free disk samples.

$\mathrm{N}$ : total number of samples statistically analysed; M: mean; $\mathrm{R}^{2}$ : coefficient of multiple determination; SD: standard error (deviation) for the $\mathrm{x}$ values (reference method values); SEC: standard error of calibration; SECV: standard error of cross-validation; SEL: standard error for the laboratory data (reference method); SEL: standard error for the laboratory data (reference method) for 8 replications with the same control sample; RPD: ratio of performance to deviation.

\begin{tabular}{lcccccccccc}
\hline Criteria & $\mathrm{N}$ & $\mathrm{M}$ & $\mathrm{SD}$ & $\mathrm{SEC}$ & $\mathrm{R}^{2}$ & $\mathrm{SECV}$ & $\mathrm{SEL}$ & SEP & Number of PLS terms & RPD \\
\hline EC $(\%)$ & 186 & 3.66 & 0.58 & 0.29 & 0.75 & 0.35 & 0.34 & 0.29 & 8 \\
KL $(\%)$ & 189 & 24.62 & 0.84 & 0.30 & 0.87 & 0.34 & 0.42 & 0.32 & 6 \\
S/G ratio & 186 & 4.03 & 0.54 & 0.17 & 0.90 & 0.20 & 0.08 & 0.18 & 2 \\
\hline
\end{tabular}

Table VI. Descriptive statistics for extractive content (EC), S/G ratio and Klason lignin (KL) content for the validation set (nonextracted disk samples).

$\mathrm{N}$ : total number of samples statistically analysed; M: mean; SD: standard error (deviation) for the $\mathrm{x}$ values (reference method values).

\begin{tabular}{lcccc}
\hline Criteria & $\mathrm{N}$ & $\mathrm{M}$ & Range & $\mathrm{SD}$ \\
\hline EC $(\%)$ & 30 & 3.66 & $2.46-4.72$ & 0.61 \\
KL $(\%)$ & 30 & 24.43 & $23.09-26.21$ & 0.79 \\
S/G ratio & 30 & 4.05 & $3.35-5.25$ & 0.50 \\
\hline
\end{tabular}

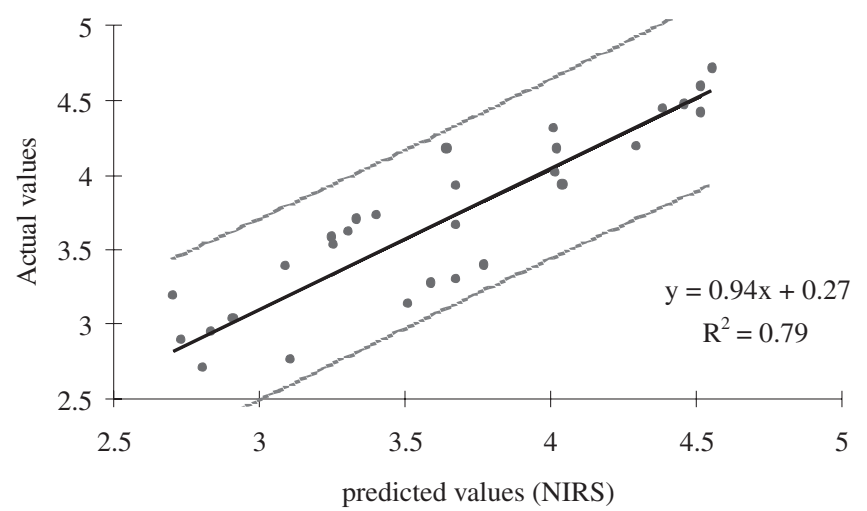

Figure 3. Correlation between laboratory values and NIRS predicted values (nonextracted disk samples) for EC, obtained for a set of 30 independent samples (95\% confidence interval).
Table VII. Descriptive statistics for extractive content (EC), S/G ratio and Klason lignin (KL) content for the validation set (extractive-free disk samples).

$\mathrm{N}$ : total number of samples statistically analysed; M: mean; SD: standard error (deviation) for the $\mathrm{x}$ values (reference method values).

\begin{tabular}{lcccc}
\hline Criteria & $\mathrm{N}$ & $\mathrm{M}$ & Range & SD \\
\hline EC $(\%)$ & 28 & 3.67 & $2.46-4.94$ & 0.62 \\
KL $(\%)$ & 29 & 24.57 & $22.96-25.91$ & 0.79 \\
S/G ratio & 30 & 4.14 & $3.22-5.14$ & 0.54 \\
\hline
\end{tabular}

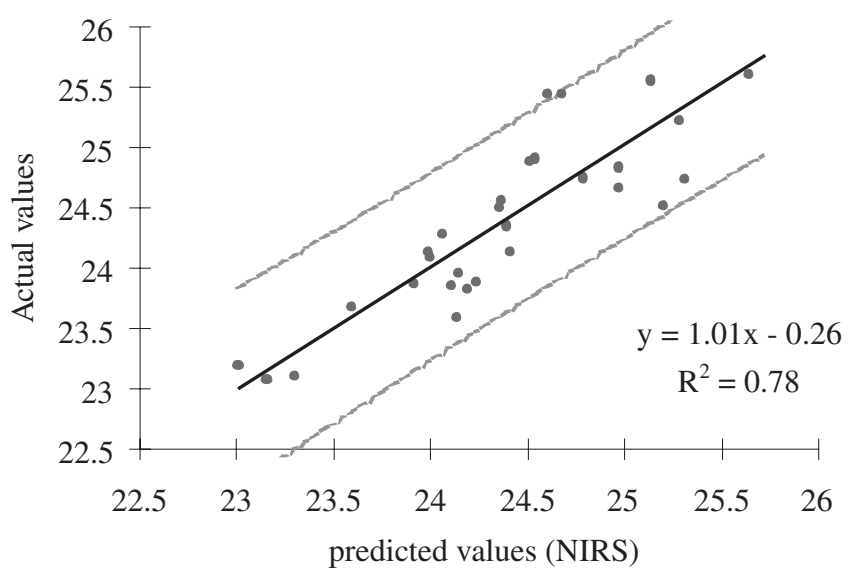

Figure 4. Correlation between laboratory values and NIRS predicted values (nonextracted disk samples) for KL content, obtained for a set of 30 independent samples (95\% confidence interval). 


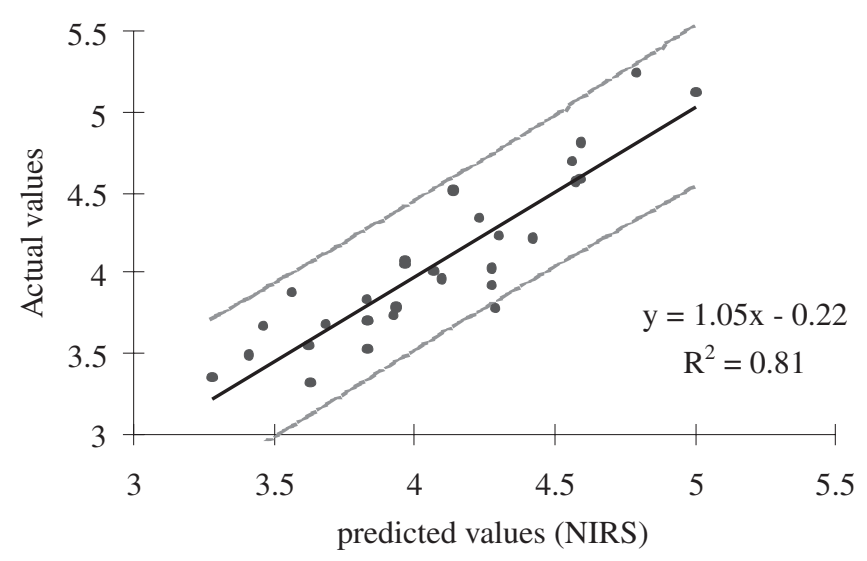

Figure 5. Correlation between laboratory values and NIRS predicted values (nonextracted disk samples) for $\mathrm{S} / \mathrm{G}$ ratio, obtained for a set of 30 independent samples (95\% confidence interval).

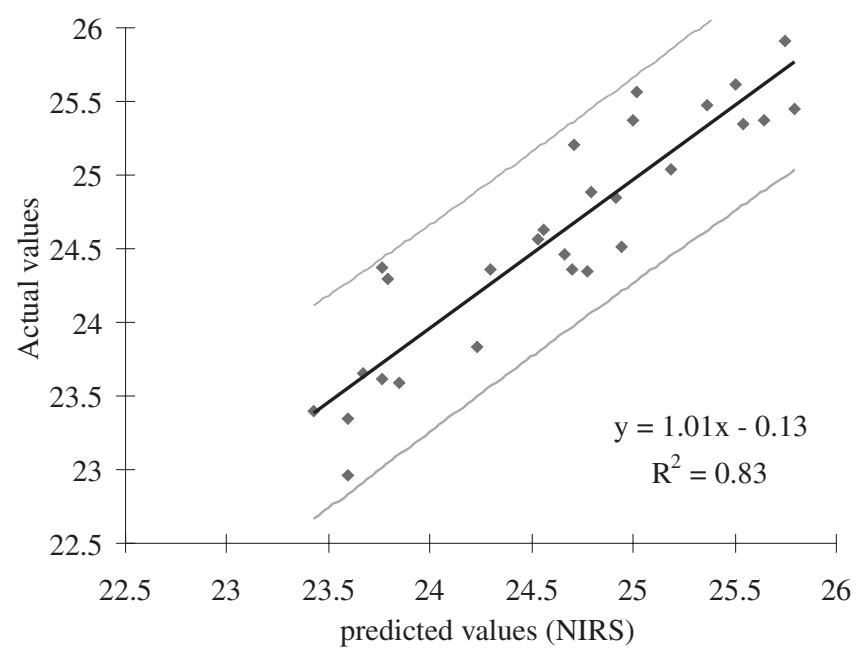

Figure 7. Correlation between laboratory values and NIRS predicted values (extractive-free disk samples) for KL content, obtained for a set of 29 independent samples (95\% confidence interval).

the $\mathrm{S} / \mathrm{G}$ ratio, which reached 0.9 for extractive-free wood. The regression slopes were all close to 1, except for the EC concerning extractive-free wood, which had a steeper slope (1.23), while the mean bias values were close to zero.

The scatter plot for residual variations versus predicted values confirmed the normality hypothesis and the independence of the data. The residual variations were centred on zero and did not vary with the predicted values.

\subsubsection{From extreme value samples}

The calibration performances for extreme value samples were slightly poorer than those obtained for nonextracted disk samples (tables $I V$ and $V I I I$ ). The RPD values were close

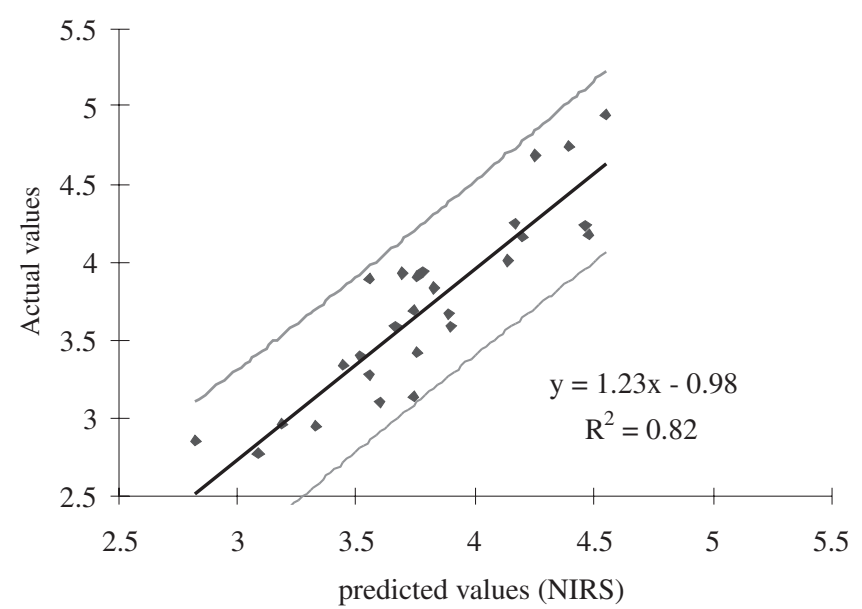

Figure 6. Correlation between laboratory values and NIRS predicted values (extractive-free disk samples) for EC, obtained for a set of 28 independent samples (95\% confidence interval).

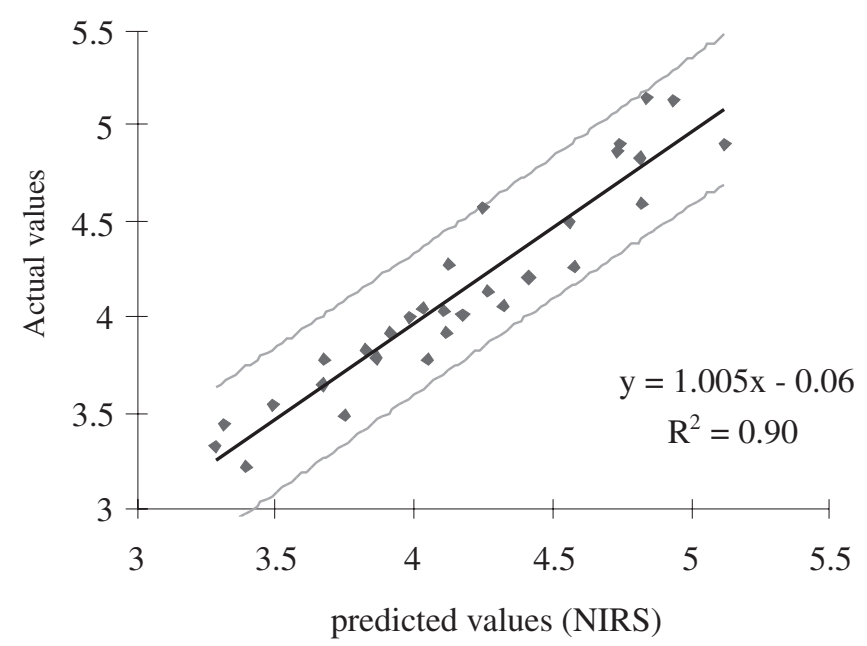

Figure 8. Correlation between laboratory values and NIRS predicted values (extractive-free disk samples) for $\mathrm{S} / \mathrm{G}$ ratio, obtained for a set of 30 independent samples (95\% confidence interval).

to 2 even though the coefficients of determination were higher. This difference could be partially explained by the low number of extreme value samples and the lower accuracy of the reference method as compared to the disk sample analyses. This was shown by a higher SEL, which could be attributed to the fact that the samples were quantitatively smaller for the chemical assays (see Section 2.2.).

Twenty samples were randomly taken from this sample set to form two subgroups for estimating the standard error of prediction (SEP). We thus obtained a calibration file containing 67 samples and a validation file containing 20 samples. LK lignin contents and $\mathrm{S} / \mathrm{G}$ ratio values for the validation samples were in line with the results obtained for the entire set (table III). The mean Klason lignin content was 26.95 and 
Table VIII. Statistics for equations established for the set of extreme value samples.

$\mathrm{N}$ : total number of samples statistically analysed; M: mean; $\mathrm{R}^{2}$ : coefficient of multiple determination; SD: standard error (deviation) for the $\mathrm{x}$ values (reference method values); SEC: standard error of calibration; SECV: standard error of cross-validation; SEL: standard error for the laboratory data (reference method) for 9 replications with the same control sample; SEP: standard error of prediction; RPD: ratio of performance to deviation.

\begin{tabular}{lcccccccccc}
\hline Criteria & $\mathrm{N}$ & $\mathrm{M}$ & $\mathrm{SD}$ & $\mathrm{SEC}$ & $\mathrm{R}^{2}$ & $\mathrm{SECV}$ & $\mathrm{SEL}$ & SEP & Number of PLS terms & RPD \\
\hline KL $(\%)$ & 84 & 26.43 & 1.43 & 0.53 & 0.87 & 0.63 & 0.58 & 0.72 & 3 \\
S/G ratio & 81 & 3.25 & 0.38 & 0.07 & 0.97 & 0.11 & 0.1 & 0.18 & 2 \\
\hline
\end{tabular}

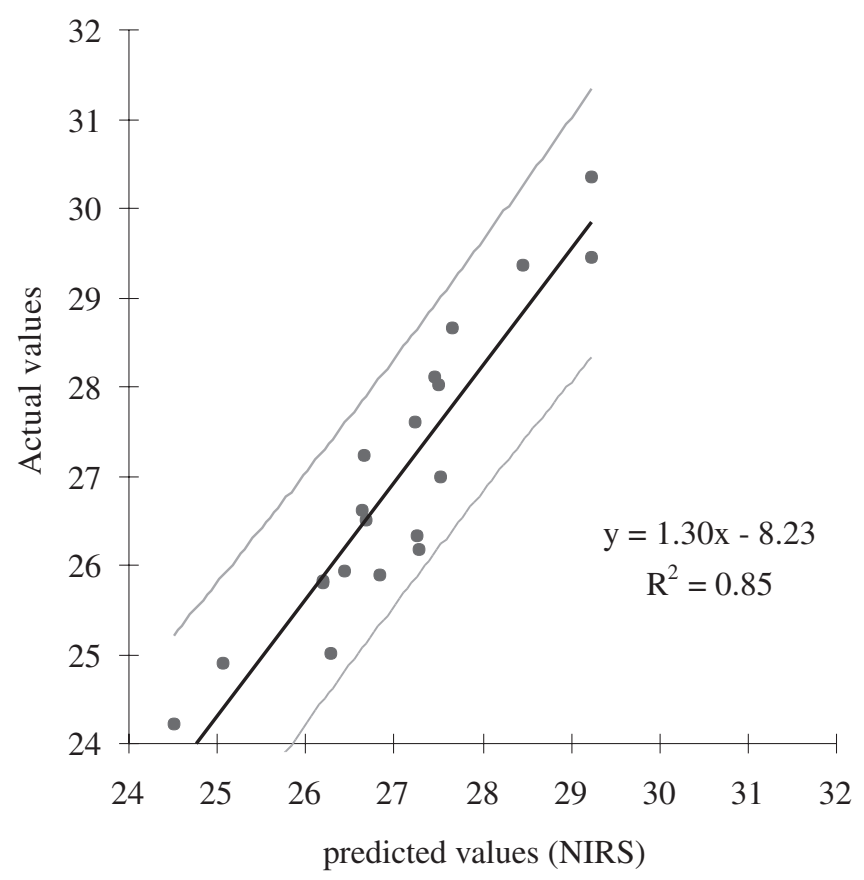

Figure 9. Correlation between laboratory values and NIRS predicted values (extreme value samples) for KL content, obtained for a set of 20 independent samples (95\% confidence interval).

the mean $\mathrm{S} / \mathrm{G}$ ratio was 3.22. The standard deviations for these two criteria were 1.64 and 0.43 , respectively. Figures 9 and 10 show linear regressions between the reference and predicted values. The coefficients of determination were comparable to those obtained from disk sample validation batches. However, the slopes and ordinates at the origin differed significantly relative to the theoretical distribution.

\subsection{Prediction of physical and mechanical properties}

The descriptive statistics for criteria analysed in the laboratory on these samples are presented in table IX. The TS and RS distributions were Gaussian. The LGS and LS distributions were not Gaussian, i.e. they were levelled off. This was due to the sampling method, which preferentially selected extreme LGS values.

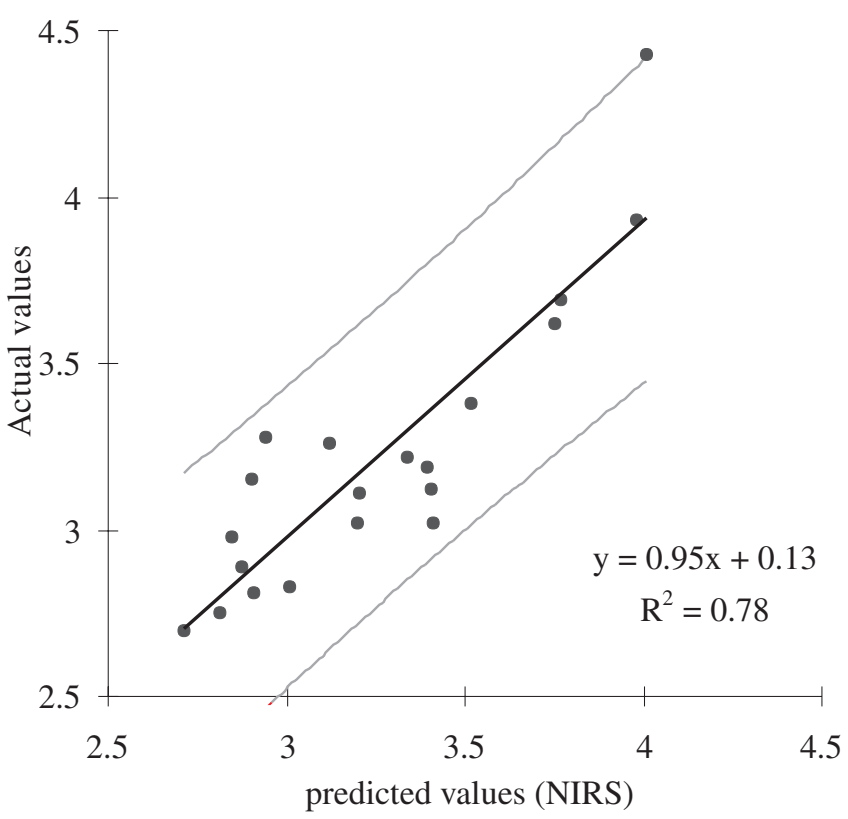

Figure 10. Correlation between laboratory values and NIRS predicted values (extreme value samples) for $\mathrm{S} / \mathrm{G}$ ratio, obtained for a set of 20 independent samples (95\% confidence interval).

No significant correlations were noted between LGS and shrinkage, or between LGS or shrinkage and the chemical characteristics, in contrast with the results reported by Baillères et al. [4] and Gril et al. [13].

The models (table $X$ ) developed for LGS, TS, RS and LS fitted the data relatively closely, except for LS, which had a coefficient of determination of 0.35 . Hence it was of no interest to develop a validation test for this criterion.

LGS, TS, and RS were predicted for a randomised set of about 20 samples using an equation previously established. The statistical criteria (mean and SD) for these samples ( $t a-$ ble $X I$ ) were comparable to those of the population from which they originated (table IX).

The coefficients of determination for the regressions calculated by comparison of the reference values with those predicted by the NIRS equations (figures 11, 12 and 13) 
Table IX. Descriptive statistics for physical and mechanical properties for the entire set of samples.

$\mathrm{N}$ : total number of samples statistically analysed; M: mean; SD: standard error (deviation) for the x values (reference method values).

\begin{tabular}{llccc}
\hline Criteria & N & M & Range & SD \\
\hline Longitudinal growth strain & 87 & 95.77 & $38-200$ & 40.05 \\
Tangential shrinkage & 89 & -0.083 & $-0.12-(-0.05)$ & 0.015 \\
Radial shrinkage & 89 & -0.039 & $-0.06-(-0.021)$ & 0.008 \\
Longitudinal shrinkage & 89 & -0.007 & $-0.0014-(-0.0106)$ & 0.0019 \\
\hline
\end{tabular}

Table X. Statistics of equations established for physical and mechanical properties.

$\mathrm{N}$ : total number of samples statistically analysed; M: mean; $\mathrm{R}^{2}$ : coefficient of multiple determination; SD: standard error (deviation) for the $\mathrm{x}$ values (reference method values); SEC: standard error of calibration; SECV: standard error of cross-validation; SEL: standard error for the laboratory data (reference method); SEP: standard error of prediction; RPD: ratio of performance to deviation.

\begin{tabular}{lcccccccccc}
\hline Constituent & $\mathrm{N}$ & $\mathrm{M}$ & $\mathrm{SD}$ & $\mathrm{SEC}$ & $\mathrm{R}^{2}$ & SECV & SEL & SEP & Number of PLS terms & RPD \\
\hline Longitudinal growth strain & 82 & 93.3 & 37.7 & 22.7 & 0.64 & 26.6 & 20.0 & 20.4 & 3 \\
Tangential shrinkage & 87 & -0.08 & 0.014 & 0.006 & 0.82 & 0.008 & 0.001 & 0.006 & 1.85 \\
Radial shrinkage & 83 & -0.04 & 0.007 & 0.004 & 0.65 & 0.005 & 0.002 & 0.007 & 4 & 2 \\
Longitudinal shrinkage & 82 & -0.007 & 0.002 & 0.001 & 0.35 & 0.001 & 0.003 & 0.003 & 1 & 2 \\
\hline
\end{tabular}

Table XI. Descriptive statistics for the physical and mechanical properties for the validation set.

$\mathrm{N}$ : total number of samples statistically analysed; M: mean; SD: standard error (deviation) for the x values (reference method values).

\begin{tabular}{llccc}
\hline Criteria & $\mathrm{N}$ & $\mathrm{M}$ & Range & SD \\
\hline Longitudinal growth strain & 18 & 89.05 & $38-147$ & 34.86 \\
Tangential shrinkage & 19 & -0.086 & $-0.12-(-0.05)$ & 0.016 \\
Radial shrinkage & 19 & -0.038 & $-0.02-(-0.038)$ & 0.008 \\
\hline
\end{tabular}

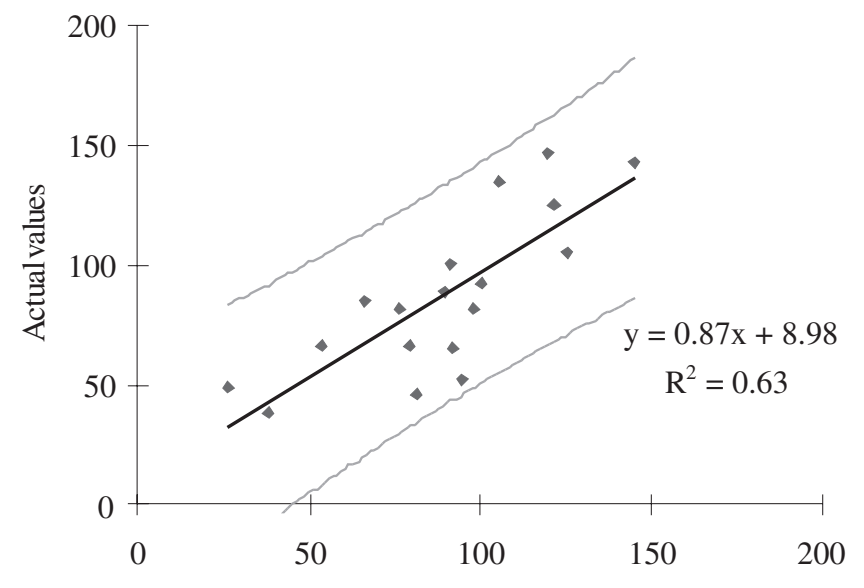

Predicted values (NIRS)

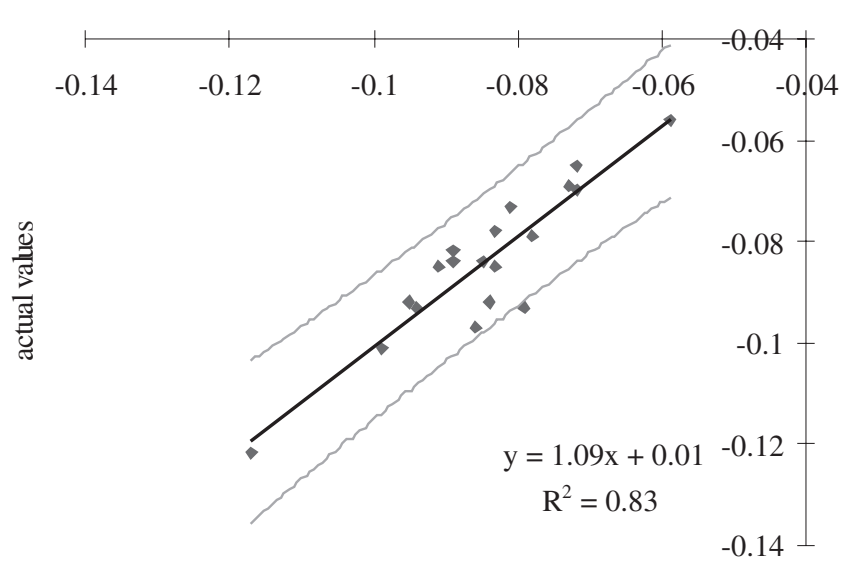

Predicted values (NIRS)
Figure 11. Correlation between laboratory values and NIRS predicted values for longitudinal growth strain, obtained for a set of 18 independent samples (95\% confidence interval).

were, by decreasing performance, $0.83,0.63$ and 0.45 for TS, LGS and RS, respectively. The regression slopes were 1.093, 0.874 and 0.724 , respectively, while the mean bias values were $0.0005,-2.241$ and 0.003 . The scatter plot for the resid-
Figure 12. Correlation between laboratory values and NIRS predicted values for tangential shrinkage, obtained for a set of 19 independent samples ( $95 \%$ confidence interval).

ual variations versus the predicted values confirmed the normality hypothesis and the independence of the data. The residual variations were centred on zero and did not vary with the predicted values. 


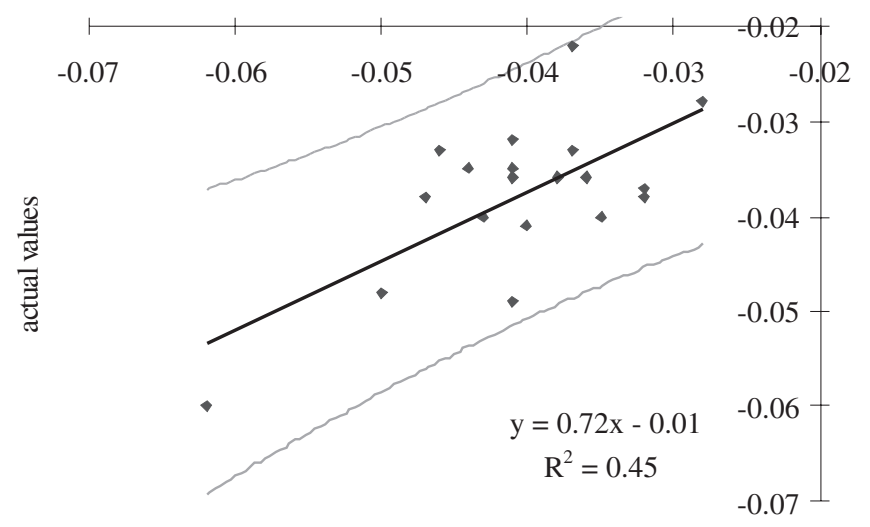

Predicted values
The RPD ratio was always above 2 but lower than 3, so full-sibs of this hybrid could only be roughly classified. NIRS calibrations based on nonextracted powder could nevertheless be used directly.

Interestingly, we obtained a good correlation between the EC and spectral data for extracted powder, which could be explained by two hypotheses. In woods with high phenolic material content, some extraneous materials are often so highly polymerized that they cannot be extracted with neutral organic solvents or with water [7,38]. Such extraneous materials remain in the wood and can be co-determined with lignin through Klason lignin analysis. On the other hand, some metabolic linkages between extractives and cell wall components could account for this result. For example, Higuchi [14] indicated that some key enzymes are involved in the induction of lignin and flavonoid biosynthesis.

The calibrations obtained for the extreme value samples were not as good as those obtained for nonextractive disk samples. The difference between the observed results could be explained by the low number of extreme value samples and the slightly higher SEL. However, the RPD remained above 2 , which once again confirmed - in a sample that differed with respect to its greater physiological maturity, its location in the sapwood, and the wood-sample volume - that these calibrations could be used effectively to predict specific chemical characteristics. The quality of the results obtained under these new sampling conditions indicated that NIRS is quite efficient for this application because it generates more targeted information and pertinent criteria on within-tree variations in a specific characteristic. This heterogeneity could be an interesting selection parameter in addition to other criteria.

These calibrations should still be used with caution because at most they can discriminate between a small number of groups in a reference population. However, the fact that NIRS can readily pinpoint individuals within a population targeted for an improvement programme could be an especially useful tool for tree breeders.

\subsection{Prediction of physical and mechanical properties}

For these calibrations, only around 88 samples were assessed, i.e. not sufficient to establish predictive models (only 20 samples for validation). For TS, $82 \%$ of the variance in the reference measurement was explained by the model. The SEC and RPD results indicated that the calibration error is sufficiently low to use the NIRS technique as a rapid screening tool. For LGS and RS, the statistical parameters were not as good. Results have been previously obtained on small samples that highlight a relationship between LGS and various physical, mechanical, anatomical and chemical properties [4, $6,13,16,24,30]$. These results explain the expected significant correlation between NIR spectral bands and some mechanical and physical properties. They indicate that the LGS measurement technique used in this study should be imtral zones. 
proved in order to increase its accuracy. Moreover, the zone responsible for the LGS value is certainly smaller than that of the samples removed, especially in the radial plane where about $80 \%$ of the stress released occurs within the first $10 \mathrm{~mm}[2,24]$. Its RPD ratio was relatively close to two, so the population could be roughly classified.

In the transverse direction, the cellular organisation and cross-sectional shape of the cells play an important role in shrinkage [29]. Radial shrinkage closely depends on anatomic factors above and beyond individual cell structure and composition. Among them, the major factor that affects shrinkage is the restraint of radial shrinkage by rays because of the low shrinkage potential and high stiffness as compared to tissues of longitudinally aligned cells. RS is therefore probably more dependent on the cellular organisation, which does not influence spectra measured by the NIRS technique on meal wood, thus leading to poor calibration quality.

The poor accuracy of the reference technique measurement, i.e. SEL was close to the SD for the set of samples ( $t a-$ ble $X$ ), was detrimental to the LS measurement. Highly efficient measurement techniques and very careful specimen preparation are necessary because of the very low degree of longitudinal shrinkage that is generally detected. We tried to boost measurement accuracy (use of a laser probe), but further metrological improvements would be required.

Finally, our results indicate that NIRS could soon be used for tree selection in forest tree breeding programmes on the basis of criteria that are otherwise seldom taken into account because they are economically and technically hard to measure on a large scale. However, the technique requires some improvements to boost its efficiency and accuracy so as to be able to more accurately distinguish between individuals in a breeding population.

From a metrological viewpoint, the entire reference method could be modified to enhance the accuracy of the sample analyses. The required precision is obviously a question of suitability for the purpose. The lignin content parameter, for instance, could be significantly improved, as demonstrated by Schwanninger and Hinterstoisser [25].

From a sampling design viewpoint, the calibration equations could be improved by increasing the number of samples and by assessing a wider span of values. The latter was not taken into sufficient account at the sampling level. A better choice of samples, i.e. especially with respect to extreme values, could enhance the quality of the prediction models.

\section{CONCLUSION}

The results presented in this study indicate that NIRS can be used to predict some major wood characteristics from wood-meal samples in eucalyptus breeding programs. Each of the major constituent groups, i.e. cellulose, hemicelluloses, lignin, and extractives, contribute uniquely to the properties and behaviour that characterise wood. How each component affects wood quality also depends on each of the other components. Prediction is thus only recommended for the characteristic properties, at the pertinent scale, which depend closely on the chemical structure and composition of the wood. Conversely, predictions will not be valid when other factors have an influence on wood properties or when the reference measurement is inaccurate or slightly variable. In the latter case, methodological and metrological improvements are possible. In fact, the quality of the calibration equation closely depends on the choice of experimental design (training samples) and also on the accuracy of the reference methods.

NIRS calibrations for wood analysis could be enhanced by:

- improving the sampling method by broadening the variability range within the calibration set;

- improving the accuracy of the reference method, particularly for mechanical and physical characteristics such as LGS or longitudinal shrinkage;

- determining the best measurement volume for samples in order to avoid local and scale effects.

Solid wood samples should be used for NIRS analysis to avoid tedious grinding operations, and to reduce analysis time to just a few minutes, as compared to several hours for traditional reference methods. This nondestructive strategy could, for instance, be used to assess increment cores.

Acknowledgements: We wish to thank Philippe Vigneron for breeding the full sib family and URPPI for field measurements in the Congo. The work was financed by a research contract from the French Ministère de l'enseignement et de la technologie (procédure biotechnologie décision No 98C0204).

\section{REFERENCES}

[1] Archer R.R., Growth stresses and strains in trees, Springer series in wood science, Springer-Verlag, 1986.

[2] Baillères H., Précontraintes de croissance et propriétés mécanophysiques de clones d'Eucalyptus (Pointe Noire-Congo): hétérogénéités, corrélations et interprétations histologiques, Thèse de l'Université de Bordeaux 1, 1994.

[3] Baillères H., Chanson B., Fournier M., Two field measurement techniques for appraising the longitudinal growth strains at the stem surface, Conference proceedings, Plant Biomechanics, Elsevier Press, Paris, 1994.

[4] Baillères H., Chanson B., Fournier M., Tollier M.T., Monties B., Structure, composition chimique et retraits de maturation du bois chez des clones d'Eucalyptus, Ann. Sci. For. 52 (1995) 157-173.

[5] Baillères H., Chanson B., Fournier-Djimbi M., Plantations d'arbres à croissance rapide et qualité des produits forestiers sous les tropiques, XI Congrès forestier mondial, Octobre 1997, Antalya, Turquie 3 (1997) 54-62.

[6] Baillères H., Castan M., Monties B., Pollet B., Lapierre C., Lignin structure in Buxus sempervirens L. reaction wood, Phytochemistry 44 (1996) 35-39.

[7] Bariska M., Pizzi A., The interaction of polyflavonoid tannins with wood cell-walls, Holzforschung 40 (1986) 299-302. 
[8] Barnes R.J., Dhanoa M.S., Lister S.J., Standard normal variate transformation and de-trending of near-infrared diffuse reflectance spectra, Soc. Appl. Spect. 43 (1989) 772-777.

[9] Bertrand D., Dufour E., La spectroscopie infrarouge et ses applications analytiques, Collection sciences et techniques agroalimentaires, Éditions Tec et Doc, 2000.

[10] Chiang V.L., Funaoka M., The difference between guaiacyl and guaiacyl-syringyl lignins in their responses to kraft delignification, Holzforshung 44 (1990) 309-313.

[11] Downes G.M., Hudson I.L., Raymond C.A., Dean G.H., Michell A.J., Schmileck L.R., Evans R., Muneri A., Sampling plantation eucalypts for wood and fibre properties, CSIRO publishing, 1997, $132 \mathrm{p}$.

[12] Effland M., Modified procedure to determine acid insoluble lignin in wood and pulp, Tappi 60 (1977) 143-144.

[13] Gril J., Sassus F., Baillères H., Combes J.G., Shrinkage variability predicted from growth strains or chemical indicators, Wood-water relation, 1st Conference of COST E8 "Performance of wood and wood-made products", Hoffmeyer P. (Ed.), Copenhagen, Denmark, 1997.

[14] Higuchi T., Biochemistry and molecular biology of wood, Springer series in wood science, Springer-Verlag, 1997.

[15] Hoffmeyer P., Pedersen J.G., Evaluation of density and strength of Norway spruce by near infrared reflectance spectroscopy, Holz Roh Werkst. 53 (1995) 165-170.

[16] Kubler H., Growth stresses in trees and related wood properties, Forestry Abstracts 48 (1987) 131-189.

[17] Martens H., Naes T., Multivariate calibration by data compression, in: Willams P.C., Norris K.H. (Eds.), Near-infrared technology in the agricultural and food industries, American Association of Cereal Chemists, Inc., Saint-Paul, USA, 1987, pp. 57-84.

[18] Michell A.J., Pulpwood quality estimation by near-infrared spectroscopic measurements on eucalypt woods, Appita J. 48 (1995) 425-428.

[19] Ona T., Sonoda T., Itoh K., Shibata M., Relationship of lignin content, lignin monomeric composition and hemicellulose composition in the same trunk sought by their within-tree variations in Eucalyptus camaldulensis and E. globulus, Holzforschung 51 (1997) 396-404

[20] Osborne B.G., Fearn T., Hindle P.H., Practical NIR Spectroscopy with application in food and beverage analysis, Osborne B.G., Fearn T., Hindle P.H. (Eds.), Longman Scientific \& Technical, Harlow, England, 1993, $227 \mathrm{p}$.

[21] Raymond C.A., Schimleck L.R., Michell A.J., Muneri A., Nondestructive sampling of Eucalyptus globulus and E. nitens for wood properties. III. Predicted pulp yield using Near infrared reflectance analysis, Wood Sci. Technol. 35 (2001) 203-215.

[22] Rolando C., Monties B., Lapierre C., Thioacidolysis, in: Stephen Y.L., Carlton W.D. (Eds.), Methods in lignin chemistry, Springer Series in Wood, Ed. Timell, Springer-Verlag, 1992, pp. 334-350.

[23] Rowell R.M., The chemistry of solid wood, Advances in chemistry series 207, Comstock M.J., Rowell R. (Eds.), The American Chemical Society, 1984.
[24] Sassus F., Déformations de maturation et propriétés du bois de tension chez le hêtre et le peuplier: mesures et modèles, Thèse de l'ENGREF en Sciences du bois, Montpellier, 1998.

[25] Schwanninger M., Hinterstoisser B., Klason lignin: modifications to improve the precision of the standardized determination, Holzforschung 56 (2002) 161-166.

[26] Schimleck L.R., Michell A.J., Determination of within-tree variation of Kraft pulp yield using near-infrared spectroscopy, Appita J. 81 (1998) 229-236.

[27] Schimleck L.R., Michell A.J., Raymond C.A., Muneri A., Estimation of basic density of Eucalyptus globulus using near-infrared spectroscopy, Can. J. For. Res. 29 (1999) 194-201.

[28] Schimleck L.R., Wright P.J., Michell A.J., Wallis A.F.A., Near-infrared spectra and chemical compositions of Eucalyptus globulus and E. nitens plantation woods, Appita J. 50 (1997) 40-46.

[29] Schniewind A.P., Berndt H., The composite nature of wood, in: Lewin M., Goldstein I.S. (Eds.), Wood structure and composition, Vol. 11, Marcel Dekker Inc., 1996, pp. 435-476.

[30] Sugiyama K., Okuyama T., Yamamoto H., Yoshida M., Generation process of growth stresses in cell walls: relation between longitudinal released strain and chemical composition, Wood Sci. Technol. 27 (1993) 257-262.

[31] Tenenhaus M., Gauchi J.-P., Ménardo C., Régression PLS et applications, Revue de Statistique Appliquée, XLIII (1995) 7-63.

[32] Thygesen L.G., Determination of dry matter content and basic density of Norway spruce by near infrared reflectance and transmission spectroscopy, J. Near Infrared Spectrosc. 2 (1994) 127-135.

[33] Williams P., Norris K., Near infrared technology in the agricultural and food industries, Williams P., Norris K. (Eds.), American Association of Cereal Chemists, Inc., St Paul, Minnesota, USA, 1990, 330 p.

[34] Williams P.C., Sobering D.C., Comparison of commercial near infrared transmittance and reflectance instruments for analysis of whole grains and seeds, J. Near Infrared Spectrosc. 1 (1993) 25-33.

[35] Wold S., Cross-validation estimation of the number of components in factor and principal components models, Technometrics 20 (1978) 397-405.

[36] Wright J.A., Birkett M.D., Gambino M.J.T., Prediction of pulp yield and cellulose content from wood samples using near infrared reflectance spectroscopy, Tappi J. (1990) 164-166.

[37] Yokoi H., Ishida Y., Ohtani H., Tsuge S., Sonoda T., Ona T., Characterization of within-tree variation of lignin components in Eucalyptus camaldulensis by pyrolysis-gas chromatography, Analyst 124 (1999) 669-674.

[38] Zavarin E., Cool L., Extraneous materials from wood, in: Lewin M., Goldstein I.S. (Eds.), Wood structure and composition, Vol. 11, Marcel Dekker Inc., 1996, pp. 321-408.

[39] Zobel B.J, Jett J.B., Genetics of wood production, Springer-Verlag, Budapest, 1995, $289 \mathrm{p}$. 